\title{
Willet's distal shoe appliance for early loss of second deciduous molar: A case report with 2 year followup
}

\begin{abstract}
:
The possibilities for space loss are even higher when second primary molars are lost early because they serve as a buttress for the eruption of first permanent molar. Distal shoe space maintainer is indicated in such type of cases. It is otherwise known as intra-alveolar appliance. In this article, we report the successful use of the distal shoe space maintainer in a 4year old child.
\end{abstract}

Key words- Space Maintainer, Distal Shoe, First permanent Molar

\section{Introduction :}

Loss of primary tooth is imminent. Primary dentition plays a crucial part in guiding the eruption of permanent teeth but premature loss of primary tooth may lead to the loss of dental arch length[1]. About $51 \%$ of the prematurely lost first primary molars and $70 \%$ of prematurely lost second primary molars result in loss of space and a consequent malposition of a permanent tooth in that quadrant[2]. Early loss of the second primary molar before the eruption of the first permanent molar necessitates the use of a specific design of an intra-alveolar space maintainer[3]. In the mandible, the eruption path is mesially and slightly lingually. The distal shoe space maintainer, as introduced by Gerber[4]. and extended by Croll[5]. The distal shoe has an extension going subgingivally to a location mesial to the unerupted first permanent molar and helps in guiding its eruption. The objective of this paper is to present a case of distal shoe space maintainer in a four year old child with 2 yr follow-up.

\section{Case Report:}

A 4 year old female child came to my clinic with the chief complaint of pain in her right lower back teeth region since 3 months. She also complains of difficulty in eating. Clinical examination revealed grossly carious 85 . (fig 1 ) Radiographic

\begin{tabular}{|l|l|}
\hline \multicolumn{3}{|c|}{ Access this article online } \\
\hline \multirow{2}{*}{$\begin{array}{l}\text { Website: } \\
\text { www.ujds.in }\end{array}$} & Quick Response Code \\
\hline $\begin{array}{l}\text { DOI: } \\
\text { https://doi.org/10.21276/10.21276/ujds.2020.6.2.2 }\end{array}$ \\
\hline
\end{tabular}

examination showed furcal radiolucency and root resorption irt 85. The lower right first permanent molar showed 7 th stage of nolla's tooth development(fig 2). Patient's medical history was non contributory. Treatment plan in this case was the extraction of 85 followed by distal shoe space maintainer..

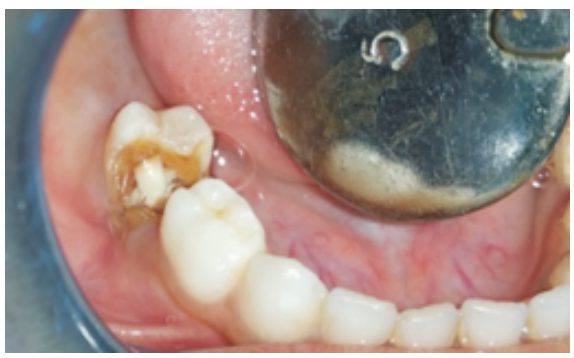

Fig. 1: pre-operative radiograph of 85

\section{${ }^{1}$ SINGHAL $M,{ }^{2}$ VASHISHTA $V,{ }^{3}$ CHAUHAN A, ${ }^{4}$ KUMAR SWARNKAR S \\ ${ }^{1,4}$ Department of Pedodontics and Preventive Dentistry, Maharana Pratap College of Dentistry \& Research Center ${ }^{2}$ Department of Orthodontics and Dentofacial Orthopedics, Sardar Patel Post Graduate Institute of Dental \& Medical Sciences \\ ${ }^{3}$ Department of Orthodontics and Dentofacial Orthopedics, Saraswati Dental College}

Address for Correspondence: Dr. Monisha Singhal Shraddha Residency Flat No. 203, Harishankar Puram Gwalior 474005

Email: monishasinghal28@gmail.com

Received : 26 July 2020, Published : 31 August 2020

How to cite this article: Singhal, M., Vashishta, V., Chauhan, A., \& Kumar Swarnkar, S. (2020). Willet's distal shoe appliance for early loss of second deciduous molar: A case report with 2 year follow up. UNIVERSITY JOURNAL OF DENTAL SCIENCES, 6(2): 68-70. 


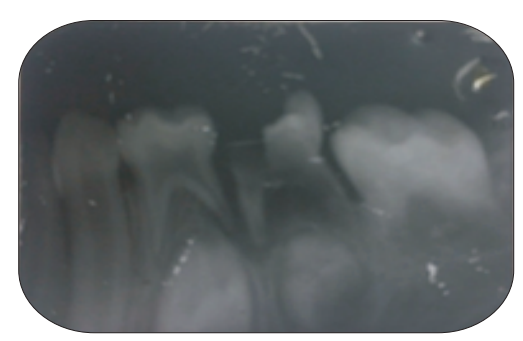

Fig. 2: IOPA radiograph

\section{Procedure:}

First visit- Suitable banding was adapted on mandibular right first molar. An alginate impression was made and band was secured in the impression. Impression was poured in dental stone and the extracted tooth was removed from the cast. The gingival extension was calculated radiographically, and was fabricated using a 21 gauge for the Stainless Steel wire in such a manner that distal extension can be seated at mesial surface of right mandibular first molar just $1 \mathrm{~mm}$ below the mesial marginal ridge. As the modification of willet's distal shoe a loop was fabricated instead of a bar to provide wider contact area for erupting permanent molar. The free ends of the loop are soldered to the band. (Fig 3)

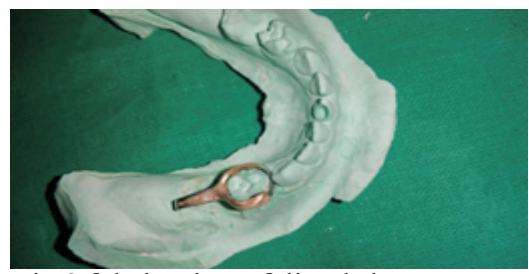

Fig 3 fabrication of distal shoe on cast

Second visit- The procedure was explained to the parents and the patient and the informed consent was taken. Extraction of 85 was done under antibiotic coverage and local anesthesia. Bleeding was controlled and the distal shoe was placed in socket so as to touch and guide the vertical eruption of mandibular right first permanent molar (Fig 4). Intraoral radiograph was taken to confirm the appropriate position of the appliance (Fig 5). And then was cemented permanently with GIC. The recalled visits were planned every 3 months to check the condition of distal shoe appliance and status of eruption of permanent teeth. After 22 months the 46 was correctly guided into the place. (Fig 6)

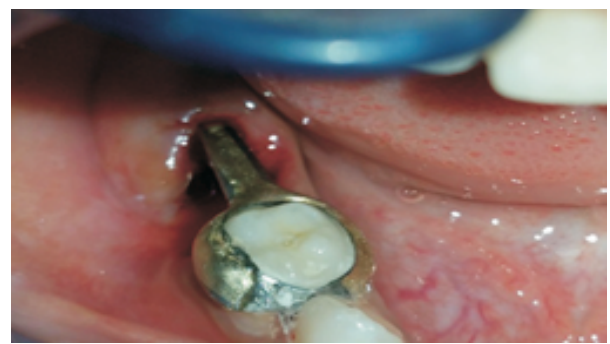

Fig 4 fabrication of distal shoe on cast

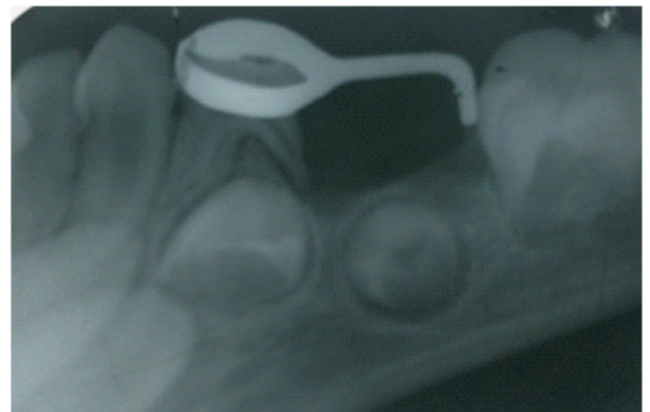

Fig. 5: Appliance cemented in patient's mouth post extraction of 85

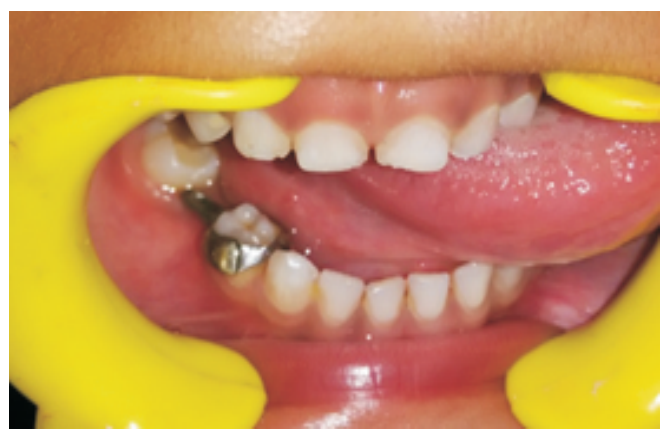

Fig. 6: 2 year's follow up showing the erupted 46

\section{Discussion:}

Mixed dentition is the most vital phase in pediatric dentistry. Proper management and guidance to the developing permanent dentition has always led to a harmonious, functional and esthetically acceptable occlusion. Early loss of primary teeth may occur due to dental caries, congenital disorder, trauma or infection, ignorance about the importance of deciduous teeth, etc, which may lead to orthodontic treatment in later in the life[5]. Various kinds of space maintainers are available depending on the tooth lost, or segment involved. Premature loss of primary second molar prior to the eruption of first permanent molar is quite a challenge for a dentist in managing the eruption of permanent dentition. Distal shoe space maintainers are frequently and successfully used in such type of cases.

Hoffding and Kisling[7] reported an increase in Class II molar occlusion and Class III molar occlusion in patients with premature mandibular second primary molar loss. In mandibular arch the 1st permanent molar have a mesioocclusal eruption pattern and it uses the distal surface of 2 nd primary molar as the buttress to guide into the position. Hence distal shoe appliance helps in the control of the path of eruption and prevents undesirable mesial migration of $1 \mathrm{st}$ permanent molar[8]. In 1929 Willett presented the first space maintainer with a distal extension for the premature loss of 
primary second molar. In 1942 Roche modified the distal extension with a V shaped intra-alveolar extension. The V shape offers a broader surface area and helps prevent rotations. The success criteria of a distal shoe space maintainer, as defined by Baroni et al and Qudeimat et al, is the successful guidance of the unerupted permanent tooth in the arch with no problems associated with the appliance[9].

Conclusion- In pediatric dentistry, the prime motive of the dentist is to give utmost benefit to the child with minimum discomfort and less chair side time. Distal shoe space maintainer fulfills all the criteria successfully which are required in the case of premature loss of 2 nd primary molars.

\section{References:}

1. Sasa IS, Hasan AA, Quadeimat MA. Longevity of band and loop space maintainers using glass ionomer cement: a prospective study. Euro Arch Pediatr Dent 2009 Jan;10(1):6-10.

2. Baume C.J; Physiological tooth migration and its significance for the development of occlusion. The biogenetic course of deciduous dentition. J Dent Res, 29; 123-132, 331-337, 1950.

3. 8. Huth KCh, Sagner T, Hickel R. Interdisciplinary rehabilitation and prevention in a case with early and extensive loss of primary teeth. $\mathrm{J}$ Clin Pediatr Dent. 2002 Winter;26(2):125-30.

4. GerberWE. Facile space maintainer. JAm Dent Assoc. 1964;69:691-694.

5. Croll TP. An adjustable intra-alveolar wire for distal extension space maintenance. J Pedod. 1980;4(4):347-353. 3

6. Nayak UA, Loius J, Sajeev R, Peter J. Band and loop space maintainer-made easy. J Indian Soc Pedod Prev Dent. 2004;22(3):134-136.

7. Hoffding J, Kisling E. Premature loss of primary teeth: Part II, the specific effects on occlusion and space in the permanent dentition. $\mathrm{J}$ Dent Child 1978;45(4):284-7.

8. Brook AH, Winter GB. Developmental arrest of permanent tooth germs following pulpal infection of deciduous teeth. Br Dent J. 1975; 139:9-11.

9. Brill WA. The distal shoe space maintainer chair side fabrication and clinical performance. Pediatr Dent. 2002;24:561-5. 